\title{
Variation in Morphological Traits among Loropetalum chinense var. rubrum Accessions
}

\author{
Zhiyi Bao ${ }^{1}$ and Bo Chen \\ School of Landscape Architecture, Zhejiang Forestry University, 311300 \\ Linan, China, and Department of Horticulture, Zhejiang University, \\ 268, Kaixuan Road, Hangzhou, Zhejiang Province, China 310029 \\ Hua Zhang \\ School of Tourism and Health, Zhejiang Forestry University, 311300 Linan, \\ China
}

Additional index words. data processing system, cluster analysis, phenotypic diversity

\begin{abstract}
Loropetalum chinense var. rubrum accessions in China have not been adequately characterized for their morphological traits. Such characterization would be helpful in the development of improved cultivars and in cultivar classification. In this study, the morphological traits of 23 accessions were evaluated in spring, summer, and autumn to determine their phenotypic diversity. Cluster analysis with average distance was performed for the main traits of leaf and flower using data processing system software. The morphological investigation indicated that the number of flowering accessions and the flower number of $L$. chinense var. rubrum in spring were more than those in autumn. Only one accession (no. 13) yielded several flowers in summer. Some accessions had the same or similar color of leaf or flower in spring and autumn. Two accessions had the same flower color in spring and autumn, whereas others showed slightly different colors in spring and autumn. The 23 entries were grouped into four clusters in spring and five clusters in autumn based on multivariate analysis of nine classification variables. Each cluster had some specific characteristics of its own. Generally, the cluster formed first because of the similarity in leaf color. The accessions with similar flower color formed subclusters within a cluster. These accessions are an important resource for the establishment of a core collection of $L$. chinense var. rubrum in the world. Several accessions with good qualities were selected and should be further tested for horticultural merit.
\end{abstract}

Loropetalum chinense var. rubrum is an evergreen, purple-leafed, medium-size shrub from Hunan Province, China (Hou et al., 2003). It is a member of the witch hazel family (Hamamelidaceae) and is defined as a variety of $L$. chinense (Creech, 1960). The gracefully layered branches are laden during spring and sporadically throughout the year with pendulous, bright-pink, spiderlike flowers. It is fast growing and tolerant to diseases and insects. Loropetalum chinense var. rubrum is versatile and can be grown in mild coastal climates in light shade to full sun, and can tolerate the more extreme winter and summer temperatures associated with other regions. As an important ornamental plant, L. chinense var. rubrum is very popular in Chinese cities and has been introduced into many foreign countries like America and Japan. For example, two selections of the hot-pink/purple-flowered $L$. chinense var. rubrum were introduced into the United States from Nihonkaki Nursery, Kawaguchi

Received for publication 3 Sept. 2006. Accepted for publication 30 Oct. 2006.

${ }^{1}$ To whom reprint requests should be addressed; e-mailbaozy@mail.hz.zj.cn.
City, Japan, by the former U.S. National Arboretum Director, John L. Creech, in September 1989 at the request of Sylvester G. March (Gawel et al., 1996). The plants rapidly entered the commercial market. In an attempt to give some order to the confusion of multiple accessions and clones, the U.S. National Arboretum named the purplefoliage form 'Burgundy', and the greenfoliage form 'Blush'. More than 15 different introductions of $L$. chinense var. rubrum have been established in North America since the late 1980s (Hou et al., 2004). Selection and registration of cultivars has been carried out since then.

In recent years, with rapid introduction and commercialization of $L$. chinense var. rubrum, much confusion concerning the identity of the cultivars has arisen. Although many investigations have been carried out by Chinese researchers (Hou et al., 2003; Huang et al., 2004; Liu and Zhang, 2001; Song et al., 1982; Tang and Zhou, 2001; Tang et al., 2003), the study of L. chinense var. rubrum in China is still in its primary stage, and accessions have not been adequately characterized for morphological traits. The extent of phenotypic diversity among $L$. chinense var. rubrum accessions throughout the world is not known. Evaluation and comparison of accessions in different seasons will be helpful in developing improved cultivars and in cultivar identification.

The objectives of this study were to 1) compare leaf and flower traits of various accessions in spring, summer and autumn; 2) characterize phenotypic diversity among these accessions using cluster analysis; and 3) select some accessions with good characters to use in the landscape.

\section{Materials and Methods}

Seedlings were collected from Liuyang City, Hunan Province, China, and planted in the $L$. chinense var. rubrum Garden at the Academic Institution of Landscape Gardening of Changsha, the capital city of Hunan Province, in 1998. Field tests were established in spring 2001. Twenty-one accessions were selected from the garden according to their different appearances of flowers in spring, and were numbered from 1 to 21 . There were two that flowered heavily in autumn of 2001, so they were added as nos. 26 and 27. The dates of investigation in spring, summer, and autumn were from 1 to 10 Apr., from 3 to 9 Aug., and from 2 to 6 Nov. respectively. Young leaf color, mature leaf color, underside color of young leaf, leaf shape, leaf length, leaf width, leaf length-towidth ratio, flower number, flower color, petal length, petal width, petal length-towidth ratio, floret number, and petal number were measured in every investigation. Also, spring shoot length and offshoot angle were measured in the summer investigation, and summer shoot length was measured in the autumn investigation. Ten observations were collected for each variable from each plant and means were calculated. The representative branches were cut from different parts of the plant and carried to the laboratory to determine leaf and flower color using the Royal Horticultural Society Color Chart under northward scattered light (Royal Horticultural Society and Flower Council of Holland, 1986).

The representative traits were subjected to variance and cluster analyses with data processing system software (Tang and Feng, 2002). Multivariate analysis has been used in many plant species to group accessions and cultivars into clusters (Berdahl et al., 1999; Naghavi et al., 2005; Steiner et al., 1998). The main traits of leaf and flower-young leaf color, underside color of young leaf, mature leaf color, leaf length-to-width ratio, flower number, flower color, petal length-towidth ratio, floret number, and petal numberwere used for classifying accessions into clusters in the current study. All qualitative data were transformed into numbers, and cluster analysis was performed using the following algorithm: 1) identify the minimum distance between any two taxa, 2) combine these two taxa as a single pair, 3) recalculate the average distance between this pair and all other taxa to form a new matrix, and 4) identify the closest pair in the new 
matrix and so on, until the last two clusters

\section{Results and Discussion} growth emerged crimson to light red. Most of the colors belonged to Greyed-Purple Group (183-187), with others in the Yellow-Green Group (144-154), Greyed-Orange Group (163-177), or Greyed-Red Group (178182). The leaf underside colors ranged from red to gray-red to gray-purple. The mature leaf color, measured in spring, ranged from brown to gray-purple to green to yellowgreen. Mature leaf length ranged from 2.06 to $5.52 \mathrm{~cm}$, and leaf width ranged from 1.28 to $3.44 \mathrm{~cm}$. The leaf length-to-width ratio ranged from 2.24 to 1.40 (Table 1).

Flower number and color. All accessions flowered in spring except nos. 16, 19, and 20. All flower colors were in the Red-Purple Group (57-74) with variation in the intensity (Table 1).

Petal size and number, and floret number. Petal length ranged from 1.34 to $2.40 \mathrm{~cm}$, and petal width ranged from 0.13 to $0.22 \mathrm{~cm}$. The petal length-to-width ratio ranged from 8.02 to 16.48 . Most accessions had four petals per floret, with several accessions containing occasional five petals per floret. There were generally five to eight florets per inflorescence (Table 1).

\section{Data from summer observations}

The young leaf color of accession nos. 10, 11 , and 12 was gray-purple (183A, 183A, and $183 \mathrm{~B}$ respectively). The young leaf color of accessions nos. 5, 6, 7, 8, 9, 13, 14, 15, 16, 17 , and 18 was gray-orange (163-177). The young leaf color of accession no. 1 was different from others, which turned green soon after new growth and was yellow-green (146A). The young leaves of accession no. 4 emerged earlier, some of which were bigger than mature leaves. Its color was green (137B). But its sprouts were still red, and turned green quickly under high temperatures in summer. All mature leaves in the investigation in summer emerged in spring, and turned green. Their colors were yellow-green (147A or 146A). Only one accession (no. 13) yielded several flowers in summer. There were four to five light-pink (62A) flowers at each branch tip.

Summer shoot length. Summer shoot length ranged from 8.48 to $18.48 \mathrm{~cm}$ (average, $10.0-16.0 \mathrm{~cm}$; Table 2). Generally, the length of summer shoots was greater than that of spring shoots.

Leaf color, size, and shape. There were a few gray-purple young leaves at the branch tips of every plant. Fewer young leaves emerged in autumn than in spring. The color of new growth was not persistent, because all summer leaves had turned green by fall. Leaf length ranged from 2.06 to $5.60 \mathrm{~cm}$, and leaf width ranged from 1.25 to $2.65 \mathrm{~cm}$. The are joined.

\section{Data from spring observations}

Leaf color, size, and shape. New spring

\section{Data from fall observations}

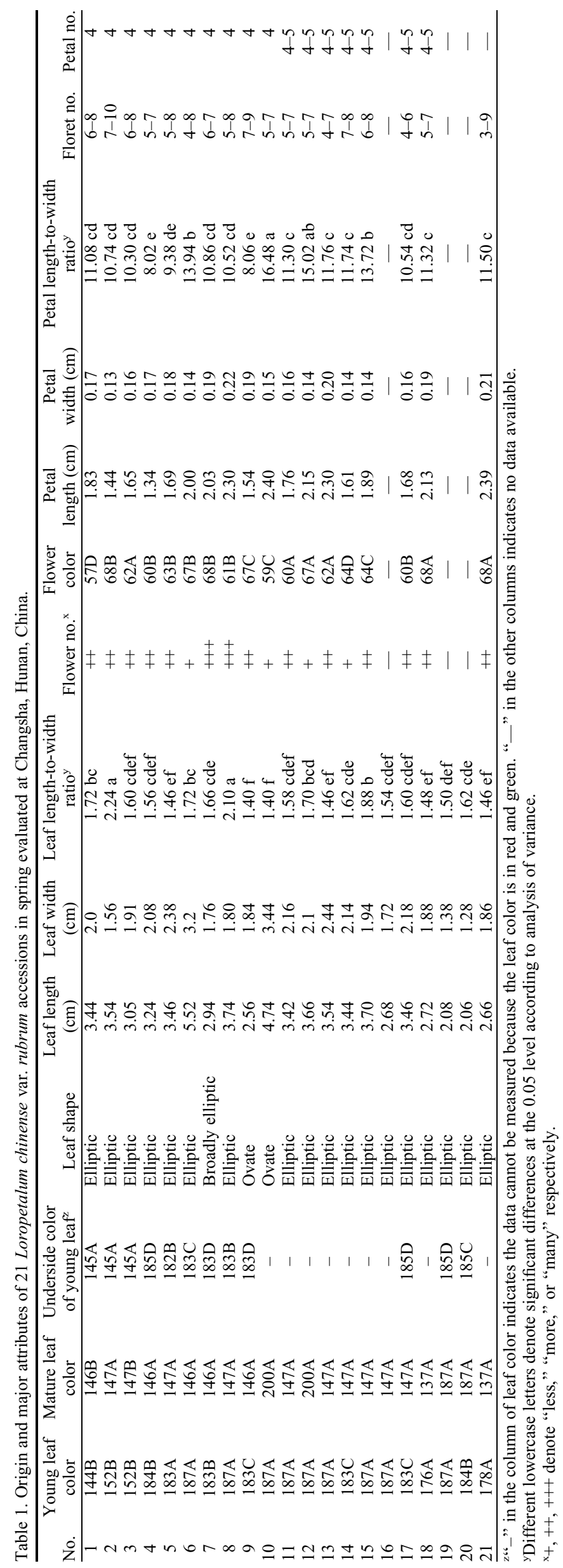




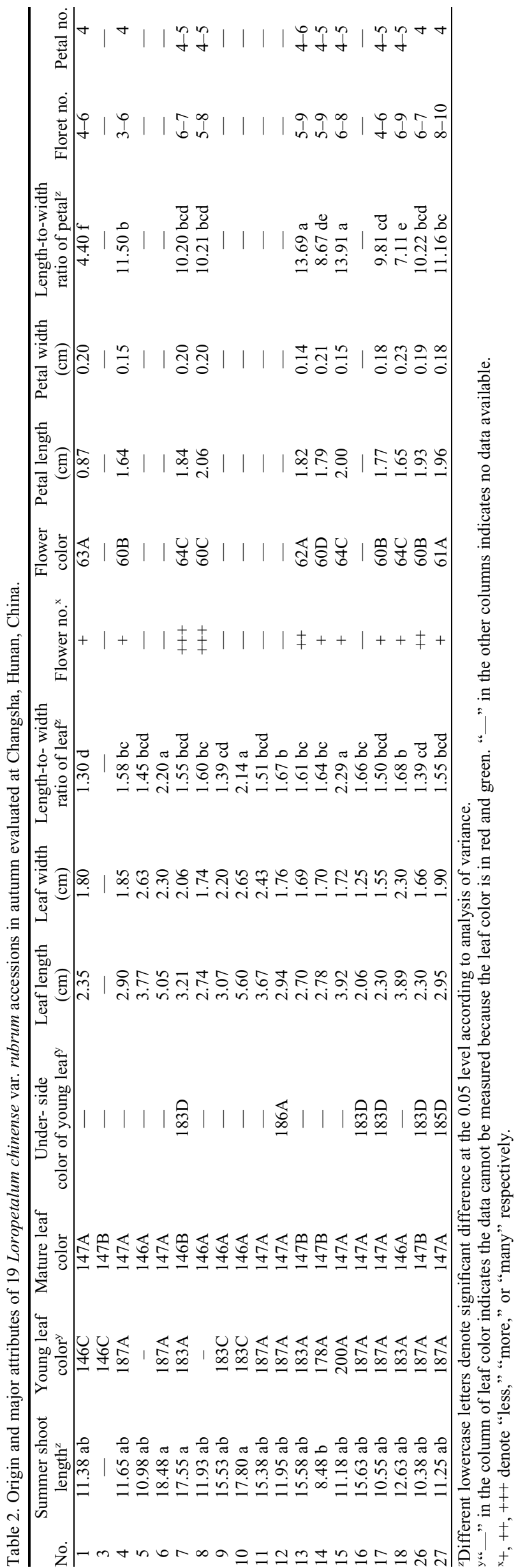

maximum leaf length-to-width ratio was $2.29 \mathrm{~cm}$ (Table 2).

Flower number and color. Only a part of the accessions flowered in autumn. The flower number of all flowered accessions in autumn was less than that in spring. Flower colors were in the Red-Purple Group (Table 2).

Petal size and number, and floret number. Petal length ranged from 0.87 to $2.06 \mathrm{~cm}$, and petal width ranged from 0.14 to $0.23 \mathrm{~cm}$. Most accessions had four to five petals per floret. There were generally four to seven florets per inflorescence, with some accessions containing occasional 9 to 10 florets per inflorescence (Table 2).

\section{Cluster analysis}

According to the data obtained in spring, the entries were grouped into four clusters at the threshold of 3.80 (Fig. 1). Cluster I included four subclusters. Subcluster I-1 included accession nos. 1, 3, 18, and 21 . Subcluster I-2 included accession nos. 5, 7, 13, 14, and 15. Subcluster I-3 included accession nos. 4 and 17 . Subcluster I-4 included accession nos. 6, 10, 11, 26, and 27. Cluster II included accession nos. 2, 8, and 9. Cluster III only included accession no. 12. Cluster IV included accession nos. 16, 19 , and 20.

According to the data obtained in autumn, the entries were grouped into five clusters (Fig. 2). Cluster I included accession nos. 1, $3,5,8,10,11,12$, and 16. Cluster II included accession nos. 6, 14, 18, and 9. Cluster III only included accession no. 4. Cluster IV included accession nos. 7, 17, 26, and 27. Cluster V included accession nos. 13 and 15.

Results from this analysis showed that the cluster grouped first as a result of the similarity in leaf color. The accessions with

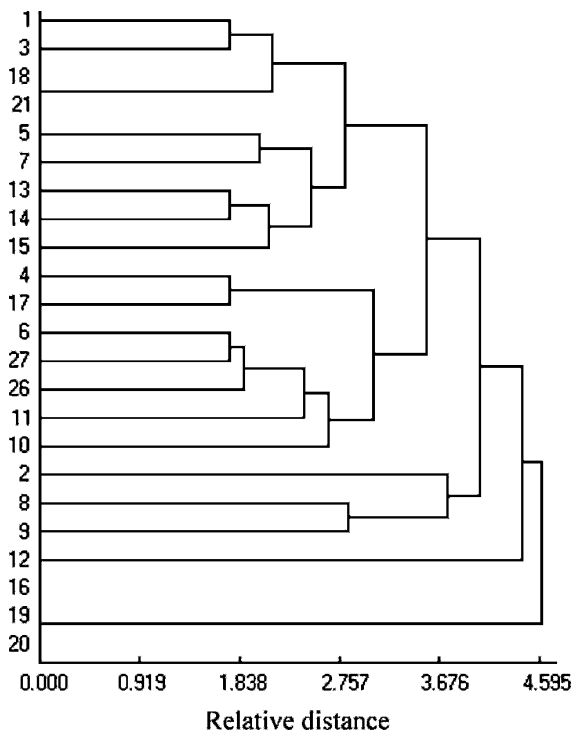

Fig. 1. Dendrogram of 21 Loropetalum chinense var. rubrum accessions in spring, with two additional accessions (nos. 26 and 27) in autumn obtained by analysis of nine morphological characterization variables. 


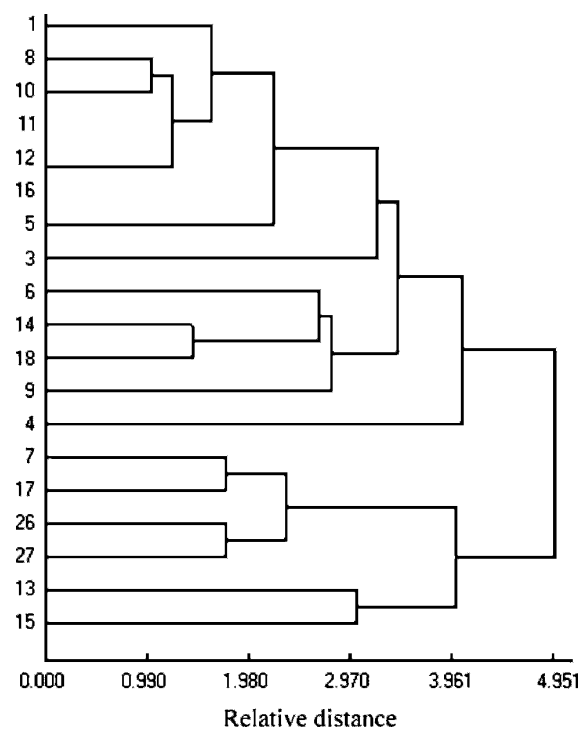

Fig. 2. Dendrogram of 19 Loropetalum chinense var. rubrum accessions in autumn (accession nos. $2,19,20$, and 21 were dead) obtained by analysis of nine morphological characterization variables.

similar flower color grouped into subclusters within a cluster; however, there were some exceptions. For example, the spring leaf colors of accession nos. 2 and 3 , both in the Yellow-Green Group, and their flower colors are similar, belonging to the Red-Purple Group. However, in the cluster dendrogram, the two accessions were in fact far apart from each other.

\section{Several accessions with good qualities}

Results from this study have implications for future plant collection and application efforts with $L$. chinense var. rubrum. After comparing the morphological traits of all accessions in different seasons, four accessions with good qualities were selected and should be further tested in the landscape. Accession no. 8 had abundant, attractive flowers in spring and autumn. Its flowers were purplish red. Flowers of accession no. 11 were a vivid red. Leaf color of accession no. 12 was dark purple, and the leaf underside color was red. Its mature leaf color was long-lasting brownish black. Accession no. 13 yielded only several flowers in the summer in this study. The color and shape of its leaves were attractive. Its mature leaves were dark glossy green and ovate. The classification and nomenclature of these plants are currently in progress.

\section{Literature Cited}

Berdahl, J.D., H.F. Mayland, K.H. Asay, and P.G. Jefferson. 1999. Variation in agronomic and morphological traits among Russian wildrye accessions. Crop Sci. 39:1890-1895.

Creech, J.L. 1960. On the distribution of Loropetalum chinense. Amer. Hort. Mag. 39:236.

Gawel, N.J., G.R. Johnson, and R. Sauve. 1996. Identification of genetic diversity among Loropetalum chinense var. rubrum introductions. J. Environ. Hort. 14:38-41.

Hou, B.X., Z.H. Cheng, F. Liu, G.F. Yu, A.Q. Yi, and Q.A. Song. 2004. Breeding selection and popularization of new variety of Loropetalum chinense var. rubrum. J. Chin. Urban For. 2: 33-35.
Hou, B.X., F. Liu, W.P. Li, X.M. Wang, G.F. Yu, and Q.A. Song. 2003. List of Loropetalum chinense var. rubrum classification system. For. Res. 16:430-433.

Huang, Q.C., L.Y. Jiang, X.H. Peng, and G.S. Hu. 2004. On resistance of Loropetalum chinense var. rubrum. J. Hunan Agri. Univ. (Nat. Sci.) 30:37-39.

Liu, D.L. and Q. Zhang. 2001. The germplasm resources of Loropetalum chinense var. rubrum and their further exploitation. Wild Plant Resources China 20:17-18.

Naghavi, M.R. and M.R. Jahansouz. 2005. Variation in the agronomic and morphological traits of Iranian chickpea accessions. J. Integrative Plant Biol. 47:375-379.

Royal Horticultural Society and Flower Council of Holland. 1986. The RHS colour chart. Royal Horticultural Society, London.

Song, P.L., C.Y. Peng, and T.X. Zhang. 1982. Tissue culture and organogenesis of Loropetalum chinense var. rubrum. Plant Phys. Com. 4:33.

Steiner, J.J., E. Piccioni, M. Falcinelli, and A. Liston. 1998. Germplasm diversity among cultivars and the NPGS crimson clover collection. Crop Sci. 38:263-271.

Tang, Q.R., Y.Y. Chen, and P.H. Zhou. 2003. Study on the stability of anthocyanin and $\mathrm{pH}$ changes in cell sap of leaves in Loropetalum chinense var. rubrum. Hunan For. Sci. Technol. 30:24-25.

Tang, Q.Y. and M.G. Feng. 2002. DPS data processing system for practical statistics. Science Press, Beijing.

Tang, Q.R. and P.H. Zhou. 2001. Comparisons of morphological characteristics and pigment contents among variants of Loropetalum chinense var. rubrum. J. Hunan Agri. Univ. (Nat. Sci.) 27:362-366. 